\title{
WEBER VERSUS HABERMAS: A PERSPECTIVA PRIVILEGIADA DO DIREITO NATURAL
}

\author{
Leonardo Jorge da Hora Pereira*
}

\section{Resumo}

Neste artigo trataremos de um tema já longamente debatido na literatura sobre teoria social, a saber, o embate entre as diferentes concepções de modernidade e de racionalização de dois grandes teóricos, Max Weber e Jürgen Habermas. No entanto, com toda a limitação de um texto desta natureza, gostaríamos de realizar esta empreitada a partir de um prisma um tanto quanto incomum. Tentaremos compreender as principais diferenças entre os diagnósticos dos dois autores a partir do modo pelo qual ambos enxergavam as modernas doutrinas jusnaturalistas.

Palavras-chave: Habermas; Weber; teoria social; direito natural; modernidade.

\section{Abstract}

In this article we will deal with a subject already extensively debated on social theory, namely, the opposition between the different conceptions of modernity and rationalization of two great theoreticians, Max Weber and Jürgen Habermas. However, with all the limitations imposed by the nature of this text, we would like to accomplish this task under a somewhat uncommon perspective. We aim to understand the main differences between the diagnostic of these two authors as a development from the way by which each one understands the modern jusnaturalistic doctrines.

Key-Words: Habermas; Weber; social theory; natural right; modernity.

* Mestrando em Filosofia, Instituto de Filosofia e Ciências Humanas UNICAMP. 
| 130 |

Weber versus Habermas: a perspectiva privilegiada do direito natural

\section{Racionalização em Weber}

De acordo com Weber, a racionalização apresenta-se em dois níveis. O primeiro é de caráter histórico-cultural, e diz respeito à diferenciação entre linhas de ação, que caracteriza a modernidade. Esse primeiro nível oferece a condição para o segundo, que remete ao interior de cada linha de ação, no plano da constituição de sua lógica intrínseca, da legalidade própria de cada qual (COHN, 2003, p. 234).

Mas o que significa de fato esta racionalização, que ocorre no interior de cada "sub-sistema" ou esfera social? A racionalização nada mais é do que o processo que confere significado à diferenciação de linhas de ação; isto é, a racionalização fornece a legalidade própria de cada esfera, os seus fins e objetivos precisos e específicos. Nessa perspectiva, o "desencantamento do mundo" pode ser lido enquanto um aumento gradativo da nitidez de significados antes mesclados e indistintos. Se no mundo tradicional, "encantado", a ação orientada pela magia se mistura à orientada pelo saber técnico, a arte se mescla à religião e esta à ciência, e os interesses de natureza política são legitimados por ideias de cunho religioso e/ou moral, o desencantamento do mundo traz justamente uma espécie de depuração dos significados atribuídos pelos agentes sociais às suas ações, que seriam despojados de suas múltiplas conotações de toda ordem, tendendo, no limite, para denotações unívocas. Essas puras denotações constituem os típicos significados aptos a se oferecerem à ação racional.

A partir da denotação pura, tem-se a possibilidade de agir de modo mais metódico, eficaz, direto e simples naquilo que concerne à escolha dos meios para a obtenção de um certo fim. Assim, essa clareza quanto aos objetivos a serem perseguidos em cada esfera permite a previsão e o cálculo, isto é, a ação racional (COHN, 2003, p. 238).

Mas como esta "decantação" de sentido se tornou possível? Ora, se antes o conteúdo ético proveniente de fundamentos religiosos organizava as relações que o indivíduo mantinha com as diferentes ordens de vida, de sorte que havia uma unidade 
de sentido no mundo, como então foi possível um "estouro" dessa razão substancial e consequentemente a liberação dos potenciais racionalizantes das diferentes esferas culturais. Entre outros fatores, temos de imaginar uma religião (já que nas sociedades tradicionais, a "doação" de sentido ao mundo tem fundamentos fortemente religiosos) que mantenha uma afinidade eletiva com essa (i) eliminação do conteúdo ético das relações sociais (despersonalização) e facilite (ii) o contato do indivíduo com as lógicas internas de cada esfera (racionalismo de domínio de mundo) (Cf. SOUZA 1997, p. 68). Tal religião foi o protestantismo; a religião que preparou o terreno para o fim das religiões como medium por excelência da integração social (Cf. COLLIOTTHÉLÈNE 1992, p. 172).

De um ponto de vista mais estrutural, Weber descreve esse processo de secularização como um descolamento crescente das esferas sociais em relação à religião. Isto está descrito na consideração intermediária dos seus Ensaios sobre Sociologia da Religião, traduzido com o título de Rejeições Religiosas do Mundo e suas direções. Neste ponto, as esferas desenvolveram a tal ponto suas racionalizações internas que acabam por constituir as suas respectivas legalidades próprias, o que gera fragmentação e tensões, primeiramente entre cada uma e a esfera religiosa: "a racionalização e sublimação conscientes das relações do homem em relação às diferentes esferas de possessão dos bens, possessão interior e exterior, religiosa e mundana, conduz a esse resultado: tomar consciência das regularidades legais internas próprias às diferentes esferas, e as deixar com isso entrar em relações de tensão mútua que permaneciam escondidos pela inocência original da relação com o mundo exterior" (WEBER apud COLLIOTTHÉLÈNE 1992, p. 152). Neste texto, Weber descreve como sucessivamente as esferas da economia e política (forças racionais) e também da arte e do erotismo (forças irracionais) entram em conflito com o universalismo ético religioso, outrora doador de sentido estrutural das sociedades das grandes religiões de salvação, para por fim descrever o apogeu destas tensões, que se dá entre a esfera religiosa e a científica. 
|132 |

Weber versus Habermas: a perspectiva privilegiada do direito natural

Com a autonomização das esferas culturais de valor, chegamos finalmente ao diagnóstico weberiano do politeísmo dos valores. Na medida em que cada esfera passa a impor sua lógica própria, o indivíduo se vê cruzado por diferentes (e muitas vezes conflitantes) linhas de ação. O processo societário de estabilização de sentido se desagrega. Uma mesma coisa pode ser vista como boa e feia, falsa e bela, má e verdadeira. Ocorre o que vai se chamar mais tarde de descentramento das estruturas de consciência, de sorte que os padrões de interpretação e julgamento do mundo se diversificam e se fundamentam de acordo com os seus próprios critérios. Isto significa que a substancialidade de matriz religiosa que outrora enraizava os sujeitos em contextos sociais aparentemente não-problemáticos foi fundamentalmente perdida. Agora o homem moderno, dada a falta de referenciais universais, experimenta um fenômeno que Weber chama de perda de sentido, o qual se verifica no âmbito da personalidade através das experiências de crise de identidade e no âmbito institucional uma crise e mudança do padrão de legitimação.

Isso não significa que a religião e a ética tornaram-se impossíveis na modernidade, mas apenas que o homem moderno também se encontra submetido a normas exteriores provenientes de estruturas racionais objetivas (economia e política), as quais são a princípio estranhas (e independentes) a considerações éticas e religiosas. A adesão a um sistema de normas éticas in foro conscientiae deixa de ter um correlato institucional imediato; por isso, para Weber, a época moderna era a época do individualismo moral. O lado positivo deste processo é que as noções de autonomia e de liberdade da subjetividade passam a ter lugar, na medida em que o encanto do universalismo e da unidade de sentido se quebrou e percebeu-se que os valores éticos superiores podem ser escolhidos e não mais impostos por um sistema moral fechado. Importante a salientar que para Weber tal escolha não era passível de determinação racional, mas era algo do âmbito estritamente passional. $\mathrm{O}$ fardo da nossa época, justamente por causa deste aspecto de escolha arbitrária e irracional dos valores, é o que ele descreve metaforicamente como "conflito entre deuses e 
demônios". A política, nessa perspectiva, é compreendida a partir de um ponto de vista essencialmente agonístico. Como sugere Schluchter, o único modo que Weber concebe de se evitar um decisionismo desenfreado se daria por meio de uma racionalidade procedural de análise de valores, em que, com a ajuda da ciência, se avalia os meios e principalmente as consequências destas tomadas de posição últimas (cf. SCHLUCHTER 2000, p. 42-3) e, com a ajuda de mecanismos institucionais de regulação de disputas (tal como o direito), tal luta se realiza por meios pacíficos. Daí a ideia de uma ética da responsabilidade, que combinaria paixão e razão numa equação balanceada. No entanto, jamais tal racionalidade procedural seria capaz de gerar alguma espécie de consenso intersubjetivo.

Vimos que o processo geral de racionalização conduz a uma autonomização das esferas culturais de valor e, consequentemente, ao desenvolvimento da suas respectivas lógicas intrínsecas. Naquilo que concerne às "esferas racionais", entre as quais contamos a economia, a política e a ciência/técnica, foi indicado que um racionalismo de domínio do mundo passa a crescentemente predominar. Tal racionalismo pode ser ainda identificado com os princípios da calculabilidade e da previsibilidade. Tendo em vista que a esfera jurídica também desponta como uma "força racionalizante", como esta crescente predominância do racionalismo de domínio do mundo se verifica neste campo específico?

\section{Weber e sua Sociologia do Direito}

Grosso modo, o que está em jogo na Sociologia do Direito de Weber é como a dialética entre racionalização formal (ou procedimental) e racionalização substantiva (ou material) se apresenta ao longo da história, principalmente naquilo que diz respeito ao surgimento do direito ocidental moderno. É importante ressaltar que todo direito possui estes dois aspectos. Simplificadamente, a terminologia weberiana parece sugerir que "formal" se refere à forma legal e "material" ao conteúdo legal 
| 134 |

Weber versus Habermas: a perspectiva privilegiada do direito natural

das leis. Assim, "se o critério procedimental (procedural) é enfatizado, estamos interessados em como as decisões são tomadas; se o critério substantivo é enfatizado, estamos interessados no conteúdo das decisões. No primeiro caso uma decisão é legitimada pelo seu procedimento, no segundo pelo seu conteúdo" (SCHLUCHTER 1985, p. 88). Isso significa que em cada versão histórica particular do direito, um ou outro aspecto pode ter prevalência sobre o outro naquilo que diz respeito à base de sua legitimação.

Além desta divisão, que diz respeito à relação entre forma e conteúdo, existe outra, que distingue o nível de racionalidade da lei. Assim, tanto o aspecto procedimental quanto o substantivo da lei podem ser racionalizados. No primeiro caso, temos procedimentos irracionais de feitura e aplicação da lei quando se aplicam meios que não podem ser controlados pelo intelecto ${ }^{1}$. No segundo, são substantivamente irracionais as decisões que são influenciadas por fatores concretos de casos particulares e não por normas abstratas passíveis de generalização.

A racionalização legal deve contemplar, desse modo, os dois componentes, sendo que, de acordo com Weber, a racionalização formal acaba prevalecendo. Por outro lado, tal como ocorre com as outras esferas sociais, a tendência da racionalização do campo jurídico só se realiza plenamente na medida em que ela constitui a sua legalidade própria, tornando o direito autônomo (ainda que não livre de influências externas) em relação a outras esferas, notadamente às da religião e da ética. Mas do ponto de vista histórico, como se dá esta racionalização legal e em que ela consiste?

\section{Weber e o Direito Natural moderno}

Weber identifica no Code Civil alguns elementos que não pertencem mais ao direito sacro e, no entanto, não se deixam reduzir a um estrito formalismo jurídico. Tais elementos, via de

\footnotetext{
${ }^{1}$ Por exemplo, o recurso ritualístico aos oráculos.
} 
regra acompanhados de uma "teatralidade epigramática", se aproximam da formulação do tipo daquelas dos "direitos do homem e do cidadão" contidas nas constituições francesa e norteamericana. Mais especificamente, trata-se de certos axiomas sobre o conteúdo de preceitos jurídicos sob a forma de postulados cuja pretensão é a de normatizar a legitimidade do próprio direito, tal como uma espécie de "direito do direito" (Cf. WEBER 1969, p. 640). Segundo Weber, o conteúdo de tais máximas ou postulados constituem o direito natural. No entanto, ele salienta que, do ponto de vista sociológico, as ideias referentes a este tipo específico de direito são tomadas em consideração no âmbito de um ordenamento jurídico e racional positivo apenas enquanto delas derivam consequências práticas para a conduta do criador do direito, isto é, enquanto exercem algum tipo de influência sobre a vida prática do direito. De fato, isso ocorreu de maneira especial no inicio da época moderna.

Weber define o direito natural como:

\begin{abstract}
O conjunto de normas vigentes preeminentemente frente ao direito positivo e com independência dele, que não deve sua dignidade a um estabelecimento arbitrário, mas pelo contrário, legitimam a força obrigatória deste. Quer dizer, o conjunto de normas que valem não em virtude de provir de um legislador legítimo [que seria a legitimação pelo procedimento], senão em virtude de qualidade puramente imanentes: forma especifica e única consequente da legitimidade de um direito que possa permanecer quando se suprimem as revelações religiosas e a sacralidade autoritária da tradição e de seus portadores (WEBER 1969: 640).
\end{abstract}

Duas observações devem ser feitas a respeito desta definição weberiana de direito natural. A primeira é que o direito natural é um fenômeno típico do processo de secularização (cf. PIERUCCI 2000, p. 138), mas que remete também à materialidade típica do direito religioso. Dito de outro modo, o direito natural é um misto 
| 136 |

Weber versus Habermas: a perspectiva privilegiada do direito natural

de racionalidade formal e racionalidade substantiva ou material, uma vez que consegue combinar, de um lado, clareza, precisão conceitual, rigor dedutivo, lógica formal, sistematicidade e abstração com, de outro, uma apreciação do direito e das normas que ainda encerra valor. Isto é, o direito natural ainda mantém a pretensão de legitimar concepções substantivas de bem e de justiça, só que lançando mão de artifícios que pretendem realizar uma autofundamentação da razão. Surgida já num mundo em processo de desencantamento e dessacralização (em particular da esfera jurídica), a doutrina do direito natural ainda acredita ser possível legitimar axiologicamente determinadas normas.

Por outro lado, em virtude mesmo do seu caráter póstradicional, o direito natural é a forma específica de legitimidade do ordenamento jurídico que emerge após um processo revolucionário. Por isso, entre os diversos fatores responsáveis pelo seu advento no limiar da era moderna, se encontra a conexão com os interesses da burguesia revolucionária.

Dado que as explicações weberianas são habitualmente pluri-causais, além de reconhecer o teor de verdade da concepção materialista da história neste caso específico, ele identifica no conceito de natureza surgido no Renascimento e na noção antiga, arraigada principalmente na Inglaterra, dos direitos racionais que possui o membro de um povo em virtude de suas nascença (birthright), direitos estes que antes eram vinculados apenas a certas camadas sociais e que posteriormente foram universalizados para todo cidadão inglês. Aliás, essa tendência à universalização, que culmina com os direitos do homem e do cidadão, deve-se, segundo Weber, à influência de elementos religiosos (notadamente anabatistas) e sobretudo ao racionalismo ilustrado dos séculos XVII e XVIII (Cf. WEBER 1969, p. 641).

Por outro lado, a legitimação jusnaturalista do direito positivo pode tomar direções diversas, podendo estar mais vinculada a condições formais ou a condições materiais. $\mathrm{O}$ tipo mais puro do direito natural formal é aquele que surgiu através das chamadas "teoria do pacto", especialmente em sua forma individualista. Segundo essa formulação do direito natural, todo 
direito legítimo repousa em um estatuto, e este estatuto se apóia, em ultima instância, em um convênio racional da vontade. Seja na forma de um contrato real primitivo de indivíduos livres, que regula para o futuro a forma de criação do novo direito estatuído. Ou então, em sentido ideal, estabelece-se que será legitimo aquele direito cujo conteúdo não contradiga o conceito de uma ordem conforme a razão, estatuído através de um acordo livre. Os assim denominados "direitos de liberdade" são o elemento essencial deste direito natural, principalmente a liberdade contratual (Cf. WEBER 1969, p. 642).

Para Weber, entre os elementos essenciais do direito natural racionalista figura o princípio de que se tem a livre disposição sobre a propriedade adquirida em virtude do contrato originário, o que implica o princípio da livre competência. A barreira formal da liberdade contratual impede o ataque aos direitos de liberdade, o que inclui a impossibilidade de submissão a uma "escravidão política" e a não violação do direito de livre disposição sobre as possessões privadas e força de trabalho.

Como se trata de direito natural, esse formalismo tem os seus limites. Os critérios materiais de julgamento do que é ou não é legítimo repousam assim nas noções de natureza e de razão. Estes dois conceitos são os grandes pressupostos substantivos desta concepção de direito. Assim, o racional (e legítimo) é derivado da ordem eterna da natureza e da lógica, que são mesclados entre si (Cf. WEBER 1969, p. 643).

Além de sua versão formal, o direito natural também se apresentou sob um caráter mais material. Historicamente, aliás, este foi posterior ao primeiro, sendo que o momento decisivo de passagem de um para o outro se deu com as teorias socialistas sobre a exclusiva legitimidade da aquisição em virtude do trabalho próprio (Cf. idem, ibidem). Pois com isso, não apenas se combate a aquisição gratuita por direito hereditário ou monopólio concedido, mas também o principio formal (procedimental) da liberdade contratual e da fundamental legitimidade de todos os direitos adquiridos por contrato, já que toda apropriação de bens passa a ser julgada de um ponto de vista puramente material, 
| 138 |

Weber versus Habermas: a perspectiva privilegiada do direito natural

isto é, em função da quantidade de trabalho que existe na causa da aquisição. Assim, a legitimidade de um direito adquirido não vincula mais a considerações jurídico-formais, mas econômicomateriais da forma de aquisição.

Se ao direito natural formal Weber conecta o interesse da classe burguesa ${ }^{2}$, ele não deixa de relacionar o direito natural material aos interesses do campesinato proletarizado: “O dogma da não suscetibilidade de apropriação da terra, enquanto nada foi produzido com o seu trabalho, quer dizer, o protesto contra a supressão da comunidade do solo, corresponde à situação de classes dos campesinos proletarizados cujo espaço restrito de alimentação os constrange a submeter-se ao jugo dos monopolizadores do solo..." (WEBER 1969, p. 644).

Weber reconhece que a doutrina do direito natural como um todo exerceu uma influência bastante considerável sobre a criação e a aplicação do direito nas sociedades modernas. Do ponto de vista formal, ele desempenhou inclusive um importante papel no fortalecimento da inclinação para o direito logicamente abstrato e, sobretudo, do poder da lógica no pensamento jurídico. Do ponto de vista material, sua influência não teve a mesma força, mas foi em todo caso importante.

No entanto, segundo o diagnóstico weberiano, as doutrinas do direito natural entram em franca decadência a partir do século XIX. Sua explicação para isso é, mais uma vez, plural. Nas últimas décadas do século mencionado, a maioria dos intelectuais adotaram um "ceticismo positivista e relativistaevolucionista" que destruiu a raiz mesma da ideia de um direito natural em geral, fundado num racionalismo universalista. Ademais,

Além da influência deste radicalismo antimetafísico, a esperança escatológica das massas buscou apoio nas profecias,

\footnotetext{
2 "A liberdade contratual e todas as disposições sobre a propriedade legítima derivadas daquela constituíam evidentemente o direito natural dos interessados no mercado, bem como na apropriação definitiva dos meios de produção" (WEBER 1969, p. 644)
} 
em vez de buscá-lo em postulados. No terrenos das teorias jurídicas revolucionárias a doutrina do direito natural foi destruída pela dogmática evolucionista do marxismo. Pelo lado da ciência oficial foi em parte aniquilada pelas esquemas comtianos de evolução, em parte pelas teorias orgânicas historicistas sobre o desenvolvimento. $\mathrm{O}$ mesmo efeito teve o ingrediente da Realpolitik que o tratamento do direito público assumiu, além do peso da moderna política de poder (WEBER 1969, p. 646).

Diante deste quadro de desencantamento geral das vias jurídicas, Weber conclui que:

Em parte devido ao racionalismo jurídico, em parte pelo ceticismo do moderno intelectualismo em geral, a axiomática jusnaturalista caiu atualmente em um grande descrédito. Em todo caso, perdeu a capacidade de ser fundamento de um direito. Comparadas com a robusta fé no caráter positivo de revelação religiosa de uma norma jurídica, ou na inviolável santidade de uma tradição secular, as normas obtidas por abstração, incluídas as mais convincentes, tem a este respeito uma estrutura demasiado sutil. Como consequência disso, o positivismo jurídico avança de uma maneira irresistível (idem, ibidem. O grifo é nosso).

A consequência disso é que a possibilidade de se atribuir ao direito como tal, em virtude de suas qualidades imanentes, uma dignidade supraempírica, isto é, um valor legitimado em bases universalistas, foi aniquilada: "Atualmente colocou-se [o direito] a nu, de maneira demasiado patente na grande maioria dos casos, e precisamente em muitas de suas determinações mais importantes, como produto e meio técnico de um compromisso de interesses" (WEBER 1969, p. 647, o grifo é nosso).

\section{Racionalização em Habermas}

Grosso modo, podemos entender a estratégia habermasiana como um empreendimento sistemático que visa a reabilitar a 
| 140 |

Weber versus Habermas: a perspectiva privilegiada do direito natural

inescapável dimensão consensual que é requerida por todo e qualquer ordenamento político. Se de um lado temos uma tradição de pensamento na modernidade que concebe a política, em última análise, a partir do paradigma do conflito, a tradição a qual Habermas parece se filiar sustenta que o consenso em torno de normas e valores considerados legítimos é a base a partir da qual as relações conflitivas e de poder podem emergir. Na medida em que a instância consensual é vista como precedente, Habermas vai poder depositar normativamente os seus prognósticos de emancipação justamente numa evolução das capacidades práticomorais e discursivas que os homens modernos dispõem para a realização de um novo consenso. Este, uma vez que será obtido a partir de um novo nível de justificação da norma, possibilitará uma tematização crítico-democrática dos fundamentos da sociedade e uma potencial mudança nas instituições sociais, de sorte a tornar a regulação do acesso aos bens sociais (materiais e ideais) mais equitativa.

Assim, o grande desafio é ancorar esta suposta evolução no âmbito prático-consensual em uma teoria sociológica da modernidade. Dado que Habermas considera a teoria da racionalização de Weber ainda como a melhor abordagem do processo de modernização social, ele vai se deter criticamente nesta última. A questão é que Habermas não pode aceitar sem mais o diagnóstico weberiano da dialética da racionalização e da modernidade, pois este último não parece conceber qualquer tipo de racionalização que tenha trazido efeitos "positivos" ou emancipatórios para a instância da regulação normativa. Pelo contrário, Weber concebe que onde houve complexificação social e diferenciação sistêmica, criou-se mais papelada, especialização, divisão do trabalho e, com isso, as massas tornaram-se mais "dóceis" e a servidão se tornou mais e mais inelutável. Por isso, Habermas terá de identificar algum déficit no diagnóstico de tempo weberiano.

No segundo capítulo da Teoria da Ação Comunicativa, Habermas faz uma análise sistemática da teoria weberiana da racionalização. Lá, após percorrer a sociologia de Weber, ele 
identifica dois problemas centrais, que no fundo estão intimamente vinculados. Primeiro, Weber concebeu a racionalização de forma seletiva, pois não explicitou todas as estruturas de racionalidade que surgiram no bojo do desencantamento das visões de mundo religiosas, mas tão-somente a racionalidade estratégico-instrumental. Segundo, Weber não analisou adequadamente a questão da legitimidade nas sociedades modernas, justamente porque ele não considerou suficientemente a dimensão consensual que é pressuposta por toda a dominação política.

O problema básico de Weber é então que, embora ele conceba o processo de autonomização das esferas e o descentramento das visões de mundo, apenas um tipo de racionalidade acaba imperando formalmente em todas as ordens autônomas da vida (talvez com exceção da esfera da arte), ainda que cada uma resguarde, do ponto de vista do conteúdo, a sua legalidade própria.

Assim, para que possa encontrar uma saída teoricamente positiva para os dilemas da modernidade, o que Habermas procura fazer é portanto estabelecer um conceito complexo de racionalidade e, a fortiori, um conceito complexo de racionalização e de modernidade. Desse modo, ao nível da modernização cultural das esferas de valor, ele vai conceber não apenas um ou dois, mas três complexos de racionalidade como resultado do processo de desencantamento das visões de mundo religiosas. São eles: (i) cognitivo-instrumental, (ii) prático-normativo e (iii) práticoestético.

Mas, de acordo com Habermas, esta linha de questionamento, mais complexa, é autorizada pela própria abordagem weberiana em dois níveis (ideias e interesses). Se partirmos da visão que as modernas estruturas de consciência condensam aquelas três formas básicas de racionalidade, então podemos pensar a racionalização societal estruturalmente possível como uma combinação das correspondentes ideias (nos domínios da ciência e tecnologia, lei e moralidade, e arte e erotismo) com determinados interesses. Para este sociólogo, este modelo deveria nos permitir estabelecer um padrão não-seletivo para a racionalização societal. 
| 142 |

Weber versus Habermas: a perspectiva privilegiada do direito natural

Em uma racionalização não-seletiva, as esferas culturais de valor têm de estar a tal ponto balanceadas, uma vez institucionalizadas, que as ordens de vida correspondentes sejam suficientemente autônomas para evitar a sua subordinação a leis intrínsecas, a ordens de vida que lhe são heterogêneas. Já um padrão seletivo ocorre quando um dos três componentes constitutivos da tradição cultural não é suficientemente trabalhado, ou quando algum deles é insuficientemente institucionalizado, ou ainda quando uma esfera predomina a tal ponto que sujeita as outras a uma forma de racionalidade que lhes é estranha.

Entre padrões seletivos e não-seletivos, percebemos que Habermas possui como tese de fundo a ideia de que as sociedades, em certo sentido, "aprendem", e que este saber disponível ao nível cultural é utilizado, ou melhor, apropriado e institucionalizado em função dos interesses materiais e ideais que estão em jogo.

O ponto forte da crítica de Habermas a Weber reside, então, na fixação deste em torno da questão da tensão entre a religião e as outras esferas, de sorte que ele não foi capaz de conceber, para o complexo de racionalidade prático-moral, uma ética não-ancorada na religião, secularizada, no mesmo nível da moderna ciência e da arte autônoma. A nosso ver, esta crítica e este realce ao caráter inacabado da racionalização ética têm como horizonte a busca de novos potenciais de conflito e emancipação, e parece integrar parte da solução habermasiana à "colonização do mundo" da vida ${ }^{3}$.

Em um segundo movimento, Habermas argumenta que a lei moderna desempenhou um papel semelhante àquele da ética protestante para a institucionalização da racionalidade instrumental. Sem regulação legal, os subsistemas de ação instrumental não poderiam se estabilizar. Assim, ele vai buscar justamente na racionalização da lei o ponto de passagem inacabado e não-religioso da racionalidade prático-moral do nível cultural para o nível societal.

${ }^{3}$ Isto é, somente com o desenvolvimento do potencial desta racionalidade prático-moral, ou então, só levando a cabo esta outra face (ainda não 
Se Habermas aceita que no mundo moderno o Estado burocratizado e o mercado capitalista são dominados pela racionalidade teleológica ou instrumental, ele não parece conceder, ao contrário de Weber, que a lei que regula as relações políticas e econômicas também seja exclusivamente considerada a partir deste ponto de vista.

Segundo Habermas, quando as ações instrumentais, baseadas no auto-interesse, se institucionalizam tanto na esfera econômica quanto na estatal, uma regulação normativa de caráter pós-tradicional passa a ser requerida. Isso porque a legitimidade não é mais pré-dada por tradições metafísico-religiosas ${ }^{4}$.

Na sua Sociologia da Lei, Weber define o caráter pós-tradicional da lei a partir de três aspectos estruturais: a positividade, o legalismo e a formalidade. Embora reconheça tais características da lei moderna, Habermas afirma que o problema fundamental é na verdade o de explicar como essa estrutura do sistema legal foi possível. Isto é, o fato que a lei moderna é funcional para a institucionalização da ação racional de caráter meios-fins não explica as propriedades estruturais em virtude das quais ela pode cumprir estas funções.

Habermas tenta explicar tais estruturas nos termos de uma incorporação das estruturas pós-tradicionais de consciência moral ${ }^{5}$. Isto é, a falha de Weber foi a de olhar a racionalização da lei exclusivamente do ponto de vista da racionalidade cognitivo-instrumental (relações objetificantes em termos de Sujeito-Objeto), negligenciando o fato de que a lei pertence evidentemente ao âmbito prático-normativo (relações normativas em termos de Sujeito-Sujeito).

desenvolvida) da racionalização, se poderá fazer frente à dominação tecnocrática e burocratizada, que se mantém a custa de uma despolitização das massas.

${ }^{4}$ Cf. HABERMAS 1984, p. 254-5.

${ }^{5}$ Cf. HABERMAS, op. cit., p. 260. 
| 144 |

Weber versus Habermas: a perspectiva privilegiada do direito natural

\section{$\mathrm{O}$ direito natural visto à luz da teoria social habermasiana}

É no contexto de sua estratégia de mostrar a parcialidade do diagnóstico weberiano da racionalização jurídica, que as doutrinas jusnaturalistas adquirem importância para o argumento de Habermas. Para ele, a positivação, a legalização e a formalização da lei significam que a validade desta não pode mais se basear na autoridade pré-dada de tradições morais ou religiosas, mas requer uma fundamentação autônoma. A consciência prática só pode satisfazer essa demanda ao nível pós-convencional. E nisso reside o elemento essencial: na medida em que a lei moderna perde os seus antigos "fundamentos últimos", de caráter religioso e moral, e deve legitimar-se autonomamente, é aqui que primeiro emerge a ideia de que normas legais são em princípio abertas a crítica e necessitam de justificação (que deve ser racional por causa do processo de descentramento das concepções de mundo) ${ }^{6}$. A partir deste momento surgem elementos de caráter pós-tradicional, tais como a distinção entre normas e princípios de ação, a noção de acordo racional acerca de regras que obrigam normativamente,o insight em torno da conexão entre universalidade e justificabilidade de normas legais, o conceito de sujeito legal abstrato com competências gerais, entre outros. Segundo Habermas, tais conceitos pós-tradicionais de lei e moralidade são primeiro desenvolvidos e sistematizados nas modernas teorias da lei natural. Aí, as normas são justificadas por indivíduos associados contratualmente que são em princípio livres e iguais ${ }^{7}$. Assim, o consenso tradicional é substituído aqui por uma validade baseada em um consenso racional (Cf. HABERMAS 1984, p. 262).

Assim, embora Weber enfatize estes três aspectos estruturais da lei moderna, ele negligencia o momento da necessidade de uma

\footnotetext{
${ }^{6}$ It is here that there first emerges the Idea that legal norms are in principle open to criticism and in need of justification" (HABERMAS 1984, p. 260).

7 Por causa do desencantamento das visões de mundo religiosas e do descentramento da compreensão de mundo, o novo consenso deve partir da perspectiva hipotética de associados que são em princípio livres e iguais (cf. idem, p. 257).
} 
justificação racional; ele exclui do conceito de lei moderna precisamente as concepções de justificação racional que surgem com as modernas teorias da lei natural no século XVII (cf. idem, ibidem).

Nas palavras de Habermas: "A lei natural racional, em suas diferentes versões de Hobbes e Locke, passando por Rousseau e Kant, até Hegel, pode ser entendida como um quadro teórico que busca fundamentar constituições organizadas legalmente para o Estado e para a sociedade" (HABERMAS 1984, p. 263). Ademais, segundo ele, em termos de racionalização ética, a lei natural racional é um passo adiante em relação à ética protestante, que ainda está ancorada na religião.

Alguém pode certamente levantar a objeção que o conceito de direitos naturais ainda tem fortes conotações metafísicas nos séculos XVII e XVIII. Entretanto, Habermas sublinha que, com o modelo de um contrato através do qual todos os associados legais, após pesar os seus respectivos interesses racionalmente, regulam a sua vida comum como associados livres e iguais, os teóricos da lei natural racional foram os primeiros a cumprir com a demanda de uma fundamental procedural da lei, isto é, de uma justificação por princípios cuja validade pode ser criticada (cf. HABERMAS 1984, p. 264). Nesse quadro, "natureza" e "razão" não requerem tanto conteúdos metafísicos particulares, mas antes elas circunscrevem as condições formais dentro das quais um acordo deve ser satisfeito caso ele queira ter força legitimadora, isto é, queira ser racional.

Assim, na leitura habermasiana, as doutrinas que fundam a lei natural em bases contratuais são uma primeira configuração daquilo que ele chama de racionalização prático-moral na instância consensual da legitimação política. É a partir daqui que ele pretende ancorar uma normatividade que aponte um potencial emancipatório. Isto constitui um ponto chave para mostrar que, mesmo num sistema de dominação legal baseada na racionalidade instrumental, já está presente esta outra face da racionalização. Isso não significa, entretanto, que já seja possível se extrair emancipação a partir daquele estágio de desenvolvimento histórico. Do contrário, a modernidade não seria um projeto 
| 146 |

Weber versus Habermas: a perspectiva privilegiada do direito natural

inacabado, mas um fato. Em todo caso, o mais importante a destacar aqui é que, embora o Estado moderno e o mercado capitalista possam significar um tipo de dominação pós-tradicional mais eficiente e sutil (como bem mostra Weber), este sistema de dominação precisa se legitimar, e esta legitimação precisa também ser racional e pós-tradicional, não no sentido cognitivo-instrumental, mas agora no âmbito prático-moral.

$\mathrm{Na}$ medida em que a incorporação institucional das estruturas de racionalidade (ideias) estocadas em nível cultural fica a cargo da dinâmica dos interesses, Habermas vê em movimentos sociais históricos como o movimento operário e o movimento feminista, tentativas de levar adiante este processo de racionalização ética via tematização e crítica da legitimidade do princípio organizacional da sociedade. É interessante notar que trata-se não mais de uma racionalização formal, mas substantiva, pois tal crítica se dá através da reivindicação de certos valores tidos como racionais e universais, como "dignidade humana" e "justiça".

Em outro texto, ainda na mesma linha argumentativa, Habermas afirma que, se fundamentos últimos não mais podem ser encarados como plausíveis, a época moderna se caracteriza por apresentar um nível de justificação no qual as próprias condições formais de justificação obtêm força legitimadora. Assim, os próprios procedimentos e pressuposições do acordo racional se tornam princípios. Segundo ele, "em teorias contratuais, de Hobbes e Locke até John Rawls, a ficção do estado de natureza ou de uma posição original também tem o sentido de especificar as condições sob as quais um acordo expressará o interesse comum de todos os concernidos - e nesta medida pode contar como racional" (Cf. HABERMAS 1979, p. 184) ${ }^{9}$.

\footnotetext{
${ }^{8}$ Cf. idem, p. 268.

${ }^{9}$ E ainda: "From Hobbes to Rousseau and Kant the leading ideas of rational agreement and self-determination were explicated to the extent that questions of justice and public welfare were stripped of all ontological connotations. This controversy dealt implicitly with the depreciation of a level of justification dependent on world views" (idem, p. 192).
} 


\section{Weber x Habermas}

A partir da comparação entre as leituras de Weber e de Habermas acerca das doutrinas jusnaturalistas e do desenvolvimento do direito moderno, fica claro que, enquanto Weber se esforça para ver nestas últimas concepções os resquícios metafísicos e substantivos de uma consideração do direito que se encontra a meio caminho do processo de racionalização formal, Habermas procura salientar a riqueza do conteúdo normativo do procedimento contratualista de justificação racional. Racional aqui no sentido prático-moral e não meramente formal. Olhando para um mesmo fenômeno, Weber vê o fim de um padrão de legitimação baseado na consideração axiológica (ou metaempírica) do direito; Habermas enxerga o início de um padrão de legitimação reflexivo e autenticamente racional. De Weber a Habermas, o que justifica uma tal diferença na avaliação do "grau de modernidade" do direito natural?

Talvez a diferença se encontre nos seus respectivos diagnósticos gerais da modernidade. Ambos concordam quanto ao fato de que a modernidade compreende a si mesma como momento de ruptura com todo fundamento teológico-religioso dos vínculos sociais. Há uma articulação central entre racionalização dos vínculos sócio-políticos e crítica aos fundamentos religiosos do poder que parece indissociável da própria produção da consciência da modernidade. Tal racionalização se realiza por meio da autonomização das esferas culturais de valor; o que do ponto de vista do sujeito, pode ser visto como um processo de descentramento das estruturas de consciência. No entanto, para Weber, tais esferas possuem uma legalidade própria que torna qualquer tentativa de unificação e hierarquização inviável. Ora, na medida em que a unidade do sentido do mundo se encontra dissolvida, qualquer programa filosófico que ainda busque formular critérios de validade mínimos para a ação e normas, que ainda desenvolva conceitos de legitimação racional que transcendam meros contextos empíricos, está fadado ao fracasso. 
| 148 |

Weber versus Habermas: a perspectiva privilegiada do direito natural

Por outro lado, Habermas direciona os seus esforços justamente para pensar a possibilidade de uma racionalidade dos fins no contexto de sociedades modernas. Por isso, ele sustenta uma noção de modernidade compreendida como momento que está necessariamente às voltas com o problema da sua autocertificação ${ }^{10}$, isto devido, entre outras coisas, ao fato de nada lhe aparecer como substancialmente fundamentado em um poder capaz de unificar as várias esferas de valores sociais. Ela não poderia mais procurar em outras épocas, ou em explicações mítico-religiosas de mundo, os critérios para a racionalização e para a produção do sentido de suas esferas de valores. Ela deve criar e fundamentar suas normas a partir de si mesma.

Weber provavelmente concordaria com a ideia de que os sentidos têm de ser produzidos. No entanto, ele relega tal produção para o domínio do irracional e do particular, ao passo que Habermas quer conceber formas, procedimentos racionais e universais, de garantia de justiça na escolha de fins, sentidos, valores e normas. Para tanto, Habermas precisa, em certo sentido, retomar as preocupações do jovem Hegel acerca das condições de possibilidade de uma comunidade ética no mundo moderno sem apelar evidentemente para vínculos de solidariedade passadistas - a fim de pensar as noções de liberdade e justiça em sentido enfático nas condições capitalistas.

Por isso, Habermas enxergou nas modernas doutrinas jusnaturalistas um conteúdo normativo fundamental: elas fazem do princípio de consenso racional a base da obrigação política do indivíduo (Cf. BENHABIB 1986, p. 30). A autocertificação da política é então compreendida como um contrato consensual entre indivíduos autônomos e portadores de direitos.

A questão básica que se abre a partir desta investigação é a de saber qual dos dois diagnósticos é o mais adequado para se compreender o projeto moderno em toda a sua complexidade. O que envolve saber também como se dá a relação atual entre facticidade e validade. Isto é, se ainda podemos falar de uma

${ }^{10} \mathrm{Cf}$. Habermas credita a Hegel a primeira formulação deste problema (Cf. HABERMAS 2002, p. 24). 
legitimação racional-universal dos fins e das normas na contemporaneidade. Mas tal problemática deve ser tratada num outro lugar, na medida em que escapa dos propósitos deste relatório e das nossas capacidades atuais.

\section{Referências}

BENHAHIB, Seyla. Critique, Norm and Utopia: A Study of the Foundations of Critical Theory. New York: Columbia University Press, 1986.

COHN, Gabriel. Crítica e Resignação: Max Weber e a Teoria Social. São Paulo: Martins Fontes, 2003.

COLLIOT-THÉLÈNE, Cathérine. Le Désenchantement de l'État: De Hegel à Max Weber. Paris: Les éditions de Minuit, 1992.

HABERMAS, Jürgen. Communication and the Evolution of Society. Boston: Beacon Press, 1979.

The Theory of Communicative Action: reason and the rationalization of society, v. 1. Tradução de Thomas McCarthy. Boston: Beacon Press, 1984.

O Discurso Filosófico da Modernidade. Tradução de Luiz Sérgio Repa. São Paulo: Martins Fontes, 2002.PIERUCCI, Antônio Flávio. "Secularização em Max Weber" in A Atualidade de Max Weber. Jessé Souza (org.). Brasília: Editora UNB, 2000.

SCHLUCHTER, Wolfgang. The Rise of Western Rationalism. Tradução de G. Roth. Los Angeles: University of California Press, 1985.

. "Politeísmo dos Valores" in A Atualidade de Max Weber. Jessé Souza (org.). Brasília: Editora UNB, 2000.

SOUZA, Jessé. Patologias da Modernidade: Um diálogo entre Habermas e Weber. São Paulo: Annablume, 1997.

WEBER, Max. Economía y Sociedad. Esbozo de sociología comprensiva. Vol. 1. México: Fondo de Cultura Econômica, 1969. 